\title{
Bioética de intervenção e pedagogia da libertação: aproximações possíveis
}

Ivone L. Santos ${ }^{1}$, Helena E. Shimizu ${ }^{2}$, Volnei Garrafa ${ }^{3}$

\section{Resumo}

O texto analisa uma aproximação entre a bioética de intervenção - abordagem teórica proposta na Cátedra Unesco de Bioética da Universidade de Brasília - e a pedagogia da libertação, teoria emancipadora desenvolvida pelo educador brasileiro Paulo Freire. Essas perspectivas foram selecionadas porque se propõem a atuar em contextos de desigualdade social, comprometidas com as dimensões sociopolíticas nos campos da bioética e da ética, respectivamente. Ao assumir a defesa intransigente das populações vulneráveis, "oprimidas" ou excluídas, instrumentalizam o debate ético, denunciando as desigualdades e defendendo um mundo com mais qualidade de vida e justiça social. Ao ressaltar o caráter ético-político que perpassa as duas teorias, o estudo conclui que ambas apontam a solidariedade como veículo de intervenção e mobilização, o que possibilita sua utilização conjunta e somatória como ferramenta teórico-metodológica na luta pelo respeito à dignidade humana e aos direitos humanos universais.

Palavras-chave: Bioética. Liberdade. Direitos humanos. Ensino. Autonomia.

\section{Resumen}

\section{Bioética de intervención y pedagogia de la liberación: aproximaciones posibles}

El artículo analiza una aproximación de bioética de intervención - enfoque teórico propuesto en la Cátedra Unesco de Bioética de la Universidad de Brasilia - y la pedagogía de la liberación, teoría emancipadora desarrollada por el educador brasileño Paulo Freire. Estas perspectivas han sido seleccionadas porque proponen actuar en contextos de desigualdad social, comprometidas con las dimensiones sociopolíticas en los ámbitos de la bioética y de la ética, respectivamente. Al tomar la defensa intransigente de las poblaciones vulnerables, "oprimidas" o excluidas, instrumentalizan el debate ético, denunciando las desigualdades y defendiendo un mundo con más calidad de vida y justicia social. Al resaltar el carácter ético/político que permea las dos teorías, el estudio concluye que ambas muestran la solidaridad como un vehículo para la intervención y la movilización, lo que permite su uso conjunto y en los totales como herramienta teórica y metodológica en la lucha por el respeto a la dignidad humana y a los derechos humanos universales.

Palabras-clave: Bioética. Libertad. Derechos humanos. Enseñanza. Autonomía.

\section{Abstract}

\section{Intervention bioethics and pedagogy for liberation: possible approaches}

The text analyzes an approximation between intervention bioethics - theoretical approach proposed in the Cátedra Unesco de Bioética at the University of Brasília - and the pedagogy for liberation, an emancipatory theory which was developed by the Brazilian educator Paulo Freire. These perspectives were selected due to the fact that they intend to act in social inequalities contexts, committed to the socio-political dimensions in the fields of bioethics and ethics, respectively. When assuming the intransigent defense of vulnerable, "oppressed" or excluded people, the ethical debate is created, denouncing inequalities and advocating a world with better quality of life and social justice. When highlighting the ethical/political character which intersects both theories, the study concludes that they point to solidarity as a mobilization and intervention tool, what enables their joint use as a theoretic-methodological tool in the fight for the respect to the human being dignity and to the universal human rights.

Key words: Bioethics. Liberty. Human rights. Teaching. Autonomy.

1. Doutoranda laurensantos@globo.com 2. Pós-doutora shimizu@unb.br 3. Pós-doutor garrafavolnei@gmail.com - Universidade de Brasília (UnB), Brasília/DF, Brasil.

Correspondência

Ivone L. Santos - Cátedra Unesco de Bioética da UnB, Caixa Postal 04451 CEP 70904-970. Brasília/DF, Brasil.

Declaram não haver conflito de interesse. 
A homologação da Declaração Universal sobre Bioética e Direitos Humanos (DUBDH) da Organização das Nações Unidas para a Educação, a Ciência e a Cultura (Unesco), em 2005 ${ }^{1}$, ampliou significativamente o escopo da bioética. Tal mudança conceitual se traduziu pela inclusão, no corpo da Declaração, de diversos princípios que permitiram a esse território inter e transdisciplinar do conhecimento transcender os limites até então preferencialmente direcionados à área biomédica e biotecnológica ${ }^{2}$. A DUBDH vem recebendo crescente reconhecimento internacional, apesar de alguns países ainda resistirem à sua formulação. Trata-se de um documento normativo não vinculante que, embora não tenha força de lei, tem mostrado potencial para funcionar como instrumento bastante útil no sentido de orientar os Estados na construção de suas legislações neste campo ${ }^{3}$.

Com a referida Declaração sobre bioética, evidenciou-se a possibilidade de construir uma bioética crítica, plural e concretamente comprometida com as pessoas mais frágeis - os vulneráveis sociais -, muitas vezes situados à margem do sistema produtivo. A partir desse novo quadro, a perspectiva é de que a bioética passe a se configurar como um conhecimento vinculado às lutas por justiça social e, desse modo, mais empenhado na defesa de melhor qualidade de vida para os necessitados. No sentido de resgatar uma bioética assumidamente política, este estudo dá visibilidade à abordagem teórica construída na Cátedra Unesco de Bioética da Universidade de Brasília, a bioética de intervenção (BI) ${ }^{4-6}$, estabelecendo um paralelo entre essa teoria e as ideias desenvolvidas pelo pedagogo brasileiro Paulo Freire, as quais, para efeitos do presente estudo, foram agrupadas sob a denominação de pedagogia da libertação ${ }^{7-9}(\mathrm{PL})$.

A perspectiva é analisar as possíveis convergências entre as teorias em questão, objetivando, por um lado, refletir sobre o quanto o pensamento de Freire ${ }^{7-9}$ tem a contribuir para melhor compreensão dos preceitos básicos da ética social, empenhada na busca de soluções para os problemas que afetam a realidade dos desamparados ou "oprimidos" sociais. Por outro, de discutir o quanto, a partir de Freire, a bioética, como ética aplicada, teria possibilidade de avançar além dos limites postos pelos conhecimentos biomédicos e biotecnológicos, assumindo papel de protagonista na construção de um mundo mais igualitário, que possa proporcionar mais dignidade para os seres humanos que vivem em condições de inacessibilidade aos seus direitos mais elementares. Na prática, trata-se de investir na possibilidade da utilização conjunta dos preceitos de ambas as teorias, como ferramentas na luta pelo respeito à pluralidade, à dignidade e aos direitos humanos universais e ao consequente aprimoramento da cidadania e da democracia.

\section{O caráter crítico e solidário da bioética de in- tervenção}

A BI, trabalhada desde os anos 1990 pelo então Núcleo de Estudos e Pesquisas em Bioética (e a partir de 2004, Cátedra Unesco de Bioética da Universidade de Brasília), ficou internacionalmente conhecida a partir do Sexto Congresso Mundial de Bioética, realizado em 2002, em Brasília ${ }^{10}$. Distinguida como tema de conferência temática de abertura oficial do evento, ficou demonstrado de forma mais sistemática, a partir de uma visão particular dos países do hemisfério Sul, a insuficiência (e até indiferença...) da bioética tradicional com relação ao agravamento das desigualdades e iniquidades sociais presentes no mundo contemporâneo: (...) as riquezas sociais permanecem nas mãos de poucos, continua crescente a depredação do meio ambiente $e$ as maiorias populacionais seguem distantes dos benefícios do desenvolvimento ${ }^{11}$.

A $\mathrm{BI}$, diferentemente da bioética tradicional, assume o compromisso de contribuir para a mudança radical desse quadro. Ao politizar seu discurso, apresenta como meta a busca da construção de espaços públicos nos quais se discutam alternativas às situações provocadas pela desigualdade social, como a extrema pobreza, o desemprego, a fome, o analfabetismo, a precarização no campo da mobilidade urbana, saúde, educação etc. Evidencia-se, assim, que a $\mathrm{BI}$ acredita na possibilidade de construção coletiva de uma sociedade mais justa e igualitária, pautada pelo estabelecimento de relações solidárias, não discriminatórias, tendo em vista garantir condições mais dignas de sobrevivência, em um mundo onde as pessoas tenham assegurado o direito à qualidade de vida ${ }^{10}$.

Concretamente, frente às iniquidades moralmente inaceitáveis, que diminuem sobremaneira as chances de vida das pessoas mais pobres ${ }^{12}$, a BI defende ações equitativas para o setor público e coletivo, capazes de responder à necessidade de justiça social, contemplando os direitos fundamentais do maior número de pessoas, pelo maior tempo possível e que resultem nas melhores consequências ${ }^{13}$. Nesse sentido, para a $\mathrm{Bl}$, a equidade é o ponto de partida para a construção de sociedades igualitárias ${ }^{14}$, democráticas e livres, à medida que favorece o reconhecimento das di- 
ferenças e possibilita que as pessoas sejam atendidas de acordo com seus contextos e reais necessidades.

Em síntese, a BI nasce do inconformismo e da indignação frente às desigualdades que afetam os países pobres, tendo como objetivo a busca de justiça social, na forma de combate permanente aos problemas que prejudicam o bem-viver ${ }^{15}$ de suas populações, especialmente as do Brasil e demais países latino-americanos. Desenvolvendo um estudo fundamentalmente crítico e pluralista, a BI aborda as situações emergentes decorrentes do rápido desenvolvimento biotecnocientífico dos últimos anos (novas tecnologias reprodutivas, genômica, transplantes de órgãos e tecidos), mas debate especialmente as situações persistentes diretamente vinculadas às condições estruturais que se mantêm nas sociedades humanas desde a Antiguidade, como a exclusão social, a miséria, as diferentes formas de discriminação, o aborto, a eutanásia etc. ${ }^{5}$

A proposta da $\mathrm{Bl}$ implica em uma releitura da bioética potteriana, incluindo nas suas reflexões e nos debates com a sociedade temas como: direitos humanos, cidadania, participação, iniquidades sociais e econômicas; responsabilização pública em saúde; solidariedade, empoderamento, emancipação etc. Em outras palavras, trata-se de uma abordagem ética que vai além dos conflitos morais cotidianos comumente registrados entre profissionais de saúde e pacientes ou entre investigadores e sujeitos de pesquisa, chamando a atenção para a realidade das nações onde a maioria da população segue lutando por condições mínimas de sobrevivência, onde o poder e a renda estão concentrados nas mãos de reduzida elite ${ }^{4,5}$.

Com isso, a BI procura prestar serviço aos cidadãos dos países periféricos ao mundo globalizado, uma vez que se apresenta como alternativa frente a algumas bioéticas despolitizadas, horizontais, distantes da realidade, deliberadamente neutras $e$ assépticas ${ }^{16}$ que, ao fecharem os olhos para a realidade, contribuem para a manutenção do status quo existente, em nome dos interesses exclusivos das "vidas desenvolvidas" dos países centrais; vidas civilizadas e, portanto, autorizadas a pensar pelos outros, usando os seus próprios critérios éticos e morais imperialistas e globalizantes ${ }^{17}$. Dito de outro modo, a BI chama atenção para a necessidade de crítica, frente ao fato de que as decisões políticas dos países periféricos são afetadas pelo fundamentalismo econômico gerado pela globalização desordenada e unilateral; a ética de mercado imposta acaba por determinar que as populações pobres continuem na pobreza e na discriminação social, enquanto os países centrais vão se fortalecendo econômica e politicamente ${ }^{18}$.

A proposta da $\mathrm{BI}$ constitui uma visão macro da bioética, ampliada e comprometida com o social, mais crítica, politizada e interventiva, com o objetivo de diminuir as disparidades constatadas ${ }^{19}$. Embora a teoria hegemônica da bioética - denominada principialismo - tenha pontos fortes como a sua praticidade e eficácia para avaliação da aplicação de critérios nas pesquisas clínicas e na relação profissionalpaciente, não estimula nem favorece reflexões sobre questões essenciais como aquelas que envolvam a participação do Estado, a definição de prioridades relacionadas com a aplicação e gestão de recursos em saúde, educação e segurança - de forma democrática, orgânica e crítica ${ }^{5}$.

A proposta da $\mathrm{BI}$ configura-se alternativa ética para se pensar os problemas sociais, até então pouco tratados pela bioética tradicional. Assim, ao constatar o caráter superficial da aplicação dos quatro princípios para assegurar o respeito aos direitos fundamentais das populações mais pobres, aproxima-se da bioética global de Potter, com a perspectiva de desenvolver-se a partir de uma visão ecológica e cotidiana, sem perder de vista a necessidade de promover a libertação e a proteção da América Latina; trata-se de uma bioética intercultural, que favorece os debates sociais na busca de soluções para os problemas concretos; enfim, uma ética institucional e política, habilitada a pensar criticamente a pobreza, a justiça, a igualdade na saúde e que, desse modo, transcende a bioética clínica ${ }^{20}$.

O fato é que, após quatro décadas de predominância do modelo principialista, a BI surge como uma das correntes da nova bioética latino-americana, oferecendo aportes importantes na busca de soluções para os problemas persistentes que afetam os países em desenvolvimento ${ }^{21}$. Na perspectiva da BI, a teoria de princípios é insuficiente também para: a) análises contextualizadas de conflitos que exijam uma certa flexibilidade para uma determinada adequação cultural; b) enfrentamento de macroproblemas bioéticos persistentes vivenciados diariamente pela maioria da população dos países latino-americanos, com níveis altamente significativos de exclusão ${ }^{22}$. Com base nisso, propõe a busca de respostas mais adequadas para os problemas e conflitos, sem abrir mão de abordálos numa perspectiva social e política.

A BI tem como foco principal os macroproblemas diretamente relacionados com os temas bioéticos persistentes que tanto prejudicam as populações dos países periféricos ao mundo central globalizado e surge, de certo modo, para preencher a lacuna 
deixada pela assimilação acrítica do check list principialista, na medida em que o principialismo - como teoria e prática - não proporciona a devida atenção e adequação às diferentes realidades culturais, sociais e econômicas dos países pobres da parte Sul do planeta. A partir da fundamentação epistemológica antihegemônica da BI, este debate, até então excluído da agenda internacional da bioética, começa a integrar as discussões em eventos científicos mundiais, sendo aos poucos incorporado em estudos e pesquisas, especialmente por bioeticistas latino-americanos. Categorias funcionais até então timidamente presentes na agenda - como responsabilidade, solidariedade, compromisso, participação e outras - passaram a fazer parte do contexto acadêmico na perspectiva de consolidação de uma bioética comprometida com os mais frágeis, que priorize os interesses coletivos em detrimento de anseios pontuais particulares e que se preocupe, inclusive, com o equilíbrio ambiental e planetário ${ }^{5}$.

Além das questões já referidas, a BI preocupase também com o tema da solidariedade, por entender que trata-se de um elemento importante de mobilização social. Nesse sentido, está incluída na sua fundamentação teórica a chamada "solidariedade crítica" 23-25 como ferramenta coadjuvante de apoio na construção da justiça social para as vidas humanas no seu amplo sentido. A solidariedade crítica se propõe a contribuir na construção de transformações político-sociais com base, entre outras formas, em voluntariados orgânicos no sentido gramsciano da palavra, orientados à alteridade, preocupados essencialmente com o outro ${ }^{25}$. As ações propostas por essa vertente crítica adicional da $\mathrm{BI}$ acontecem pela ação concreta de grupos organizados e deve constituir-se em uma instância social com identidade própria, referencial teórico específico e espaços de ações e intervenções que privilegiem radicalmente o respeito ao pluralismo moral e a construção de transformações sociais includentes ${ }^{26}$.

Tal caminhada incorpora a luta pela inserção crescente do maior número possível de indivíduos e grupos nos processos de tomada de decisão, problematizando de modo agudo as formas tradicionais de decidir politicamente. As bases do tipo de voluntariado proposto pela BI estão diretamente compromissadas com a proposta de uma intervenção tríplice, voltada para as dimensões civil, política e social dos grupos e instituições. Uma de suas fontes de inspiração é justamente a solidariedade crítica, que situada nas relações intrínsecas que perpassam a vida social das pessoas compreende propostas de transformação a partir tanto do envolvimento desinteressado e contu- maz verificado nos grupos tradicionais de voluntários quanto do discurso da militância e práticas políticas geradoras de mobilização social e que se estabelecem pelos movimentos de protesto e do confronto, sempre que necessário ${ }^{17}$.

Os projetos delineados pelo voluntariado orgânico são desenvolvidos a partir de práticas militantes, solidárias, críticas, autocríticas e transformadoras da realidade social. Para a $\mathrm{BI}$, os grupos de voluntários orgânicos definem suas ações nos campos da justiça, dos direitos humanos, da mobilização permanente e da luta política; sem perder de vista a necessidade de práticas essencialmente dialógicas e socialmente comprometidas. É desse modo que a BI reforça sua relação com uma solidariedade crítica, que tenha como base o que seus idealizadores chamam de "consequencialismo solidário" ${ }^{17}$.

Em suma, a BI parte do princípio de que questões relacionadas à qualidade de vida, à ética e à política não podem ser tratadas da mesma forma em todos os lugares do mundo, independentemente dos contextos em que as situações ocorram. Tais questões, quando provenientes de países periféricos, que sofrem mais gravemente com desigualdade, pobreza e violência, não podem ser tratadas com as mesmas estratégias e ferramentas usadas pelos países centrais ${ }^{5}$. Assim, a Bl cumpre um papel político, solidário e público à medida que torna mais perceptível o cotidiano das populações necessitadas, trazendo para o debate as questões sanitárias, sociais e ambientais, até então minimizadas pelo "véu da ignorância" de uns e não identificada pela indiferença ou cegueira de outros ${ }^{27}$.

\section{A ética universal na pedagogia da libertação}

A ética universal do ser humano, ferramenta teórica da PL proposta por Paulo Freire 7,8 , presente em todos os seus escritos e especialmente na sua obra Pedagogia do oprimido, de 1970, configura-se como um discurso orgânico e indignado com as situações de injustiça que perpassam a realidade das populações pobres e socialmente desfavorecidas no mundo. Nesse sentido, a PL conclama os oprimidos a tomarem consciência das situações-limite postas pela realidade excludente e a lutar com esperança e denodo ${ }^{28}$ contra as injustiças, assumindo a busca permanente pela conquista da autonomia e libertação.

Segundo Freire, a condição de humanos dota os indivíduos de capacidade ético-política para intervir no mundo, em busca de refazê-lo, de reinventá-lo a cada instante. Os humanos são, assim, seres do iné- 
dito viável ${ }^{7}$, vez que são continuadamente inacabados, abertos à possibilidade de renovação e de transformação e, por conseguinte, aptos à luta por mais humanidade. Com isso, o autor afirma sua crença na humanidade e na luta por uma realidade melhor para todos - na qual as pessoas não sejam impedidas de se desenvolver plenamente, aprimorando suas capacidades ou potencialidades ${ }^{29}$; um mundo onde não haja espaço para a exploração, discriminação e violência ${ }^{7-9}$.

Evidencia-se que a PL tem caráter fortemente solidário, voltado para a necessidade de reparar as injustiças do mundo, garantindo a todos os humanos, independentemente de cor, nacionalidade, sexo etc., o direito de ser mais ${ }^{9}$. A ética freiriana condena a exploração da força de trabalho (...) iludir o incauto, golpear o fraco e indefeso, soterrar o sonho e a utopia (...) ética que se sabe afrontada na manifestação discriminatória de raça, de gênero, de classe ${ }^{30}$ e que, portanto, recusa qualquer situação de violência que afronte os direitos humanos fundamentais e a dignidade humana. Entretanto, essa ética proposta por Freire não será dada gratuitamente. Nas palavras do autor, a liberdade não se recebe de presente, é bem que se enriquece na luta por ele, na busca permanente (...) ${ }^{31}$.

Caberá aos prejudicados pela lógica capitalista a tarefa de lutar, individual e coletivamente, para modificar a situação ditada pela regras opressoras do mercado - atualmente ainda mais fortalecidas pela prevalência da ideologia dominante da globalização. Freire, preocupado com as injustiças que tendem a se eternizar e com a possibilidade de um discurso homogêneo que paralise homens e mulheres, minando suas possibilidades de luta e de liberdade, faz severa crítica ao mundo tecnologizado: o discurso da globalização que fala da ética (...) procura disfarçar que ela [ética de mercado] vem robustecendo a riqueza de uns poucos e verticalizando a pobreza e a miséria de milhões ${ }^{32}$. Para ele, ir contra a insensatez da lógica ditada pelo capitalismo globalizante, mais que um direito, é um dever, um compromisso ético de lutar pela libertação de todas as condições históricas de negação dos direitos dos esfarrapados do mundo ${ }^{33}$.

Vale ressaltar que o primeiro passo para a busca da libertação é que as pessoas se deem conta da realidade que as cerca, tomando consciência de suas condições como seres no mundo. Mas a tomada de consciência, embora seja o ponto de partida, não é suficiente. É fundamental que os oprimidos, a partir do conhecimento dos limites impostos pela opressão, não permitam que tais limitações se imponham como algo imutável, impossível de ser modificado ${ }^{7}$. Na perspectiva freiriana da $\mathrm{PL}^{7-9}$, o resgate de valo- res humanos universais interessa a todas as pessoas; o que significa que a conquista da liberdade para os oprimidos, garantindo-Ihes condições de humanizarse, devolverá também àqueles que oprimem a dignidade perdida nas suas posições de opressores. Para Freire, não há nenhuma vitória nem benefício, do ponto de vista humano, naqueles que oprimem: ao impedir que os outros sejam mais, os opressores também se colocam numa posição de ser menos ${ }^{8,9}$, numa condição inautêntica de não liberdade.

Assim, a desumanização a que estão submetidos aqueles que estão à margem do sistema capitalista ${ }^{28}$, que não se verifica somente neles, devido ao seu potencial humano roubado, mas também, embora de forma diferente, naqueles que o roubam, é pura distorção da vocação humana para ser mais. A desumanização é desvirtuamento possível na história, mas jamais vocação histórica ${ }^{7,8}$. A defesa de Freire, nesse sentido, é de uma luta solidária pela superação das "situações-limite" nas quais as pessoas se humanizam, ao mesmo tempo em que constroem, individual e coletivamente, novos sentidos e formas de estar no mundo ${ }^{28}$.

Ao defender a solidariedade, Freire se opõe radicalmente ao capitalismo, assumindo a luta contra esse sistema político cuja natureza anti-solidária, sustentada por perversa lógica mercantil, provoca a fome e a miséria no mundo ${ }^{8,9}$. Assim, o autor nega o individualismo e a competitividade exacerbada da lógica capitalista; denuncia o mal-estar produzido pela ética de mercado que a mantém e anuncia a solidariedade como estratégia de luta; em decorrência, assume o compromisso histórico de, junto com os oprimidos, lutar para superar as injustiças sociais, promovendo, solidificando e instaurando a ética universal do ser humano ${ }^{8,9}$. Para firmar esse pacto com a solidariedade e a ética, Freire propõe um projeto pedagógico educativo e libertador, voltado para a construção de um ambiente favorável a uma práxis democrática e participativa, que tenha como pressuposto fundamental o desenvolvimento da autonomia dos educandos.

A autonomia, na perspectiva de Freire, foi sempre considerada como contraponto à dependência cultural a que todos os oprimidos estão submetidos. Ser autônomo, para o autor, é ter a condição histórica de assumir a dependência derivada de sua própria finitude, tornando-se livre para superar as barreiras que impedem a sua existência autêntica; de modo que os outros sejam outros e não meros modelos ajustados às conveniências dos demais ${ }^{34}$. Sendo assim, a autonomia pessoal e individual está diretamente relacionada com a autonomia coletiva e vincu- 
lada à solidariedade e a vida em comunidade; o que significa que, ao mesmo tempo em que cada humano é corresponsável pela autonomia do outro, ninguém é sujeito da autonomia de ninguém ${ }^{35}$. A autonomia, de acordo com a PL, é uma conquista, resultado de um processo contínuo de conscientização.

Em suma, o homem não tem condições de participar ativamente da vida em sociedade, transformando-a quando assim julgar necessário, se não for ajudado, se não tiver as condições necessárias para se dar conta do real e tomar as decisões adequadas para suprir suas necessidades; dando prosseguimento a sua contínua tarefa de busca de humanidade. Nesse sentido, Freire propõe uma educação "problematizadora" ${ }^{9}$, que não se furta a aguçar a curiosidade do educando, possibilitando ao mesmo o desvelamento crítico da realidade, motivando-o a participar ativamente na construção do próprio conhecimento. Freire, segundo Dussel, descobriu ser impossível uma educação - que não seja mero "adestramento" - sem que o educando seja protagonista, educando-se a si mesmo; conduzindo, de forma particular e intransferível, seu próprio processo de conscientização e libertação ${ }^{36}$.

Em trecho intitulado A conscientização em Paulo Freire - em sua conhecida obra Ética da libertação: na idade da globalização e da exclusão -, Dussel discorre sobre a teoria do pedagogo brasileiro, afirmando que para Freire o ponto de partida do processo de conscientização, capaz de conduzir os educandos à consciência crítica, é justamente a superação das situações-limite postas pela realidade em que se encontram. A perspectiva é que o educando - oprimido - possa superar a consciência ingênua em prol da consciência crítica; a cultura do silêncio em prol da pronúncia da realidade e do mundo; a mistificação em prol da desmistificação. Mas esta não é tarefa das mais fáceis. $O$ oprimido não conhece a liberdade e não está de imediato preparado para enfrentá-la, pois tem alojada em sua consciência a sombra dos valores do opressor. Para expulsar a sombra da opressão precisará da ajuda do outro, que incentive seu processo de conscientização e contribua na busca de libertação ${ }^{36}$.

O fato é que seres humanos não lutam contra forças incompreensíveis, com importância desconhecida, cujas formas concretas e contornos históricos não percebam. A realidade somente será modificada quando os oprimidos se derem conta das mudanças possíveis e das suas possibilidades de participação efetiva nas mesmas ${ }^{8}$. Daí a importância, para Freire, de uma pedagogia verdadeiramente libertadora, que problematize a realidade, que tenha como proposta uma práxis que favoreça o desenvolvimento da consciência crítica e a superação da consciência ingênua; que possibilite a todos uma leitura crítica do mundo; a consequente denúncia da realidade opressiva ou injusta e o reconhecimento da necessidade de luta por sua transformação.

É imprescindível, em Freire, a leitura crítica da realidade como antídoto ao que Arendt ${ }^{37}$ vê na contemporaneidade: um mundo cada vez mais tomado pela violência, onde as pessoas não mais se ocupam em buscar consensos, em pensar no coletivo; onde as situações-limite são vistas como barreiras intransponíveis e a esperança é diluída em meio ao caos político. Para Freire ${ }^{8}$, é justamente por meio da educação que se abre a possibilidade de denúncia desse mundo violento e feio e do anúncio de que é perfeitamente possível a construção coletiva de um mundo mais belo, solidário, onde todas as pessoas tenham a oportunidade de ser felizes Segundo ele, compete a todos os seres humanos a responsabilidade éticopolítica de lutar, com radicalidade, para tornar as sociedades menos perversas, injustas e excludentes. Transformar a realidade, ajustando-a à necessidade de todos, é um direito e um dever que deve ser levado a sério, individual e coletivamente.

Em outros termos, uma vez que cada oprimido se dê conta da realidade opressora e compreenda as possibilidades de mudança, torna-se necessário o seu engajamento junto aos demais, com o compromisso de modificar os contextos desfavoráveis ao desenvolvimento de suas potencialidades; nas palavras de Freire há uma responsabilidade ética, social, de nós todos no sentido de tornar a nossa sociedade menos $m^{\prime}{ }^{38}$. Cabe a ressalva de que, para Freire, um mundo mais justo, mais solidário e mais humano não deve ser encarado como um projeto a ser desenhado para os oprimidos e injustiçados; torna-se necessário que os próprios oprimidos pensem suas condições de vida e, neste caso, qualquer proposta que não parta deles deve, no mínimo, ser pensada com eles. Nessa perspectiva, os "condenados da terra" jamais serão objetos de piedade ou caridade, devendo ser tratados como sujeitos capazes de autonomia; em condições de se resgatarem, libertando a si mesmos, aos opressores e ao mundo, de toda e qualquer determinação que os impeçam de ser mais ${ }^{9}$.

Diálogo entre a bioética de intervenção e a pedagogia da libertação

$\mathrm{O}$ aspecto que mais aproxima a BI da PL é que ambas as teorias se configuram como projetos éti- 
co-políticos construídos em defesa das populações fragilizadas, especialmente aquelas em situação de desamparo tanto pelo agravamento das desigualdades e iniquidades globais quanto em nível local, pela ausência do Estado em setores que requerem indispensável atuação pública. No texto Inclusão social no contexto político da bioética ${ }^{3}$, publicado em 2005, a BI incorporou à sua fundamentação a categoria "libertação", decisiva em sua relação de aproximação com as ideias de Freire, aqui debatidas. $\mathrm{Na}$ quele texto, a bioética é pioneiramente introduzida na seara freiriana, iniciando uma aproximação em prol da interpretação e busca de soluções para os persistentes problemas que há séculos prejudicam a vida de grande parte das populações vulneráveis: os excluídos pela ética de mercado ${ }^{3,6}$.

Segundo a BI, a busca da inclusão do pensamento de Freire na bioética pode contribuir para fundamentar as discussões éticas em saúde, favorecendo medidas de inclusão social e estimulando a construção de sistemas sanitários mais adequados e acessíveis. Ou seja, ajudando a criar ambientes públicos favoráveis à concretização de realidades sociais mais solidárias, com mais qualidade de vida para as populações excluídas ${ }^{3}$. A BI, portanto, se recusa a ficar apenas teorizando frente às iniquidades socioeconômicas que tão fortemente impactam a vida de boa parte das pessoas, especialmente nos países em desenvolvimento. Preocupada, como a $\mathrm{PL}$, com os excluídos do sistema produtivo e com aqueles indivíduos cujos padrões de sobrevivência não atendem a critérios mínimos do que se entende por qualidade de vida, a BI chama a reflexão para o debate, para a militância e para a luta.

A perspectiva da $\mathrm{Bl}$ é, em outros termos, fortalecer os laços entre os cidadãos, ampliar a noção de coletividade e de pertencimento a uma mesma sociedade, reiterando a importância do compartiIhamento solidário em prol da busca de soluções públicas e coletivas para os problemas de interesse comum ${ }^{3}$. Para a $\mathrm{BI}$, especialmente a partir da DUBDH, a bioética pode lutar pelo empoderamento, pela libertação e pela emancipação dos condenados da terra ${ }^{39}$. Com tais palavras, a partir de Freire e com ele, a $\mathrm{BI}$ assume mais explicitamente a necessidade de engajamento pelo reconhecimento das injustiças e pela conquista concreta da autonomia de homens e mulheres no contexto do mundo contemporâneo. A BI - como ética aplicada e socialmente comprometida - reforça a territorialidade política da bioética, estimulando a bioética tradicional, até então voltada exclusivamente para os conflitos biomédicos, a comprometer-se com a realidade dos desam- parados, especialmente com a realidade dos povos do hemisfério Sul.

Um ponto central da presente discussão é o caráter político presente nas duas teorias aqui estudadas, que deve ser analisado na sua relação indissociável com a ética. Freire, embora não tenha dedicado um livro especificamente à (bio)ética, traz em suas obras forte apelo ético a favor da vida e na defesa incondicional da dignidade humana. Assim, numa de suas primeiras obras - certamente a mais conhecida -, Pedagogia do oprimido, Freire declara seu compromisso com os esfarrapados do mundo $e$ aos que neles se descobrem e, assim descobrindo-se, com eles sofrem, mas, sobretudo, com eles lutam ${ }^{40}$. Desse modo, o autor anuncia que a causa dos excluídos também é sua, devendo se estender como motivação para a luta de todos aqueles que conseguem se indignar com as injustiças e as maldades de um mundo movido pela lógica do consumo; onde o ter se sobrepõe ao ser; onde a competitividade exacerbada acaba por corromper a natureza humana, desviando-a de sua vocação histórica para a "amorosidade", a generosidade e a solidariedade ${ }^{7}$.

$\mathrm{O}$ fato é que a $\mathrm{BI}$ incorporou ao seu discurso e prática um dos aspectos mais importantes da proposta política de Freire: a compreensão de que homens e mulheres são sujeitos históricos, corpóreos, cuja natureza está permanentemente em construção, por se fazer ${ }^{6}$, o que resulta no fato de que não há verdades absolutas, estanques, eternas; o conhecimento, como produção humana, é também histórico, permeado de dúvidas e incertezas; reconhecer o caráter histórico do saber significa tomar consciência de que o mesmo é produção social, movido pelo dinamismo da práxis (ação/reflexão), da curiosidade e da criatividade resultante do processo de conscientização que se dá ao longo da existência humana.

A expectativa de Freire é que, ao tomar consciência da realidade, homens e mulheres alienados se reabasteçam de esperança ${ }^{8}$, podendo, desse modo, ver com os próprios olhos e desenvolver, por si mesmos, a capacidade de projetar suas vidas para que efetivamente atendam a seus interesses e necessidades individuais e coletivas. $\mathrm{Na} \mathrm{BI}$, essa tomada de consciência, seguida por um processo de conscientização permanente, em busca de superação, pode resultar na problematização de esquemas de receitas e modelos éticos, antes meramente copiados para serem seguidos acriticamente; podendo os mesmos, a partir de então, ser substituídos por propostas ou planos conectados aos contextos diversos da realidade em análise; ao mesmo tempo 
em que as decisões passem a ter por base estudos sérios e profundos dos problemas concretos vividos pelos diversos sujeitos ${ }^{5}$.

Mais especificamente, essa atitude crítica, no caso da $\mathrm{BI}$, tem como consequência a recusa à assimilação acrítica da teoria dos princípios ${ }^{5}$, também conhecida como principialismo. A BI defende, como Freire, que não existem soluções prontas, pré-fabricadas e determinadas para os problemas detectados, em detrimento da práxis daqueles que os vivenciam. Para a $\mathrm{Bl}$, é indispensável que os países do hemisfério Sul comecem a olhar seus problemas com os próprios olhos e não a partir de olhares alheios, bem como é fundamental que suas delicadas contradições e problemas passem a ser pensados a partir de seus próprios cérebros ${ }^{5}$.

Nesse sentido, qualquer iniciativa que desconsidere a vocação dos seres humanos como presenças corpóreas conscientes no mundo, vocacionadas ao diálogo, à participação, responsabilidade, é castradora e inautêntica ${ }^{41}$. Em suma, ao apostar na crítica como alternativa à busca de soluções para os problemas bioéticos, a $\mathrm{Bl}$, igualmente às propostas contidas na PL de Freire ${ }^{7-9}$, vê problemas em tratar as questões relativas à vida das pessoas com indiferença e falta de compromisso, a partir de fórmulas prontas, importadas sem o devido "filtro" de outras realidades e latitudes.

A luta de Freire, com a qual concorda a BI, é para que os países do Sul tomem consciência de suas próprias realidades e cada ser humano, a seu modo, tome para si a tarefa de construir coletivamente uma sociedade diferente que, sendo dona de si mesma, tenha os cidadãos como protagonistas de suas histórias; trata-se de uma sociedade disposta a se descolonizar ${ }^{17}$ e cortar as correntes que prejudicam seu desenvolvimento e a tornam objeto de interesses estranhos, desarticulados com seus próprios modos de vida ${ }^{41}$ ou, como no dizer de Fanon ${ }^{42}$, uma sociedade que se autoliberasse do compromisso firmado com o opressor em assimilar a sua cultura e nela aventurarse; comprometendo-se a fazer suas as formas de pensamento dos burgueses colonizadores.

Para que os países do Sul se descolonizem, entretanto, é imprescindível reconhecer que o conhecimento, devido a seu caráter mutável, exigirá sempre daqueles que o dominem, que se apropriem dos objetos a serem conhecidos, sem jamais descuidar da necessidade de assumir uma posição crítica, ética, inquietante e criativa. Na verdade, (...) se realmente queremos superar os desequilibrios entre Norte e Sul, entre poder e fragilidade, entre economias fortes e economias fracas, não podemos prescindir da ética ${ }^{43}$ universal do ser humano; uma ética que tenha como base a defesa dos direitos fundamentais de todos os seres humanos; que assuma o compromisso solidário de lutar pelo resgate da dignidade humana e a consequente construção de um mundo socialmente mais justo, inclusivo e igualitário.

Para Freire, qualquer ação que leve os seres humanos à passividade e à mecanização, que não exija o mínimo de elaboração e reelaboração crítica, resultará num saber superficial que tenderá a atrofiar a vocação humana para o debate, para o contraditório, para a práxis ${ }^{9}$. Da mesma forma, ao perceber o caráter insuficiente da bioética principialista e constatar que as necessidades dos mais frágeis eram até então mundialmente desconsideradas nas discussões bioéticas, a BI tomou para si a responsabilidade de problematizar e pluralizar tal área de conhecimento, tornando-a mais adequada à diversidade e complexidade dos problemas que afligem especialmente as populações pobres da banda Sul do mundo.

Assim, em sintonia com Freire, a BI incorpora ao seu discurso categorias até então pouco conhecidas na bioética, como conscientização, solidariedade, compromisso etc., na perspectiva de ampliar e politizar o campo de ação de tal conhecimento, distanciando-se do caráter aparentemente imparcial ou neutro, imposto pelo chamado principialismo ${ }^{44}$. Evidencia-se a importância de se traçar um paralelo entre a BI e a PL de Paulo Freire. O humanismo proposto pela PL, fundado na luta a favor dos excluídos sociais, vai ao encontro dos preceitos que norteiam a BI.

Com e a partir do pensamento de Freire, a $\mathrm{BI}$ manifesta-se claramente a favor da sua luta pela libertação dos oprimidos; oprimidos pelas injustiças, oprimidos pela miséria, pela fome, pela "malvadez" dos donos do poder. Além disso, tanto para Freire como para a BI, a libertação não será resultado de ações individualistas, mas de uma relação afetiva com os outros, como consequência da solidariedade para com os vulneráveis e do compromisso em lutar pelo resgate de sua dignidade. Trata-se de se solidarizar com os que estão à margem não somente do consumo, mas de serviços essenciais como saúde, educação, segurança etc., firmando um compromisso irrevogável com todos os que sofrem com discriminação e estigmatização, para que, juntos, possam se engajar na construção de um mundo socialmente mais justo.

Mas Freire recusa a solidariedade assistencialista praticada por aqueles que, por não acreditarem na capacidade dos excluídos e por pena, agem de forma essencialmente paternalista, não contribuin- 
do em nada com a transformação da realidade opressora em que o oprimido está inserido. Suas ideias estão absolutamente em consonância com Selli e Garrafa ${ }^{45}$ que, conforme apontado acima, desenvolveram a ideia da solidariedade crítica, que tem como eixo norteador a participação democrática das pessoas em sociedade, sem relações de dependência ou interesses em beneficiar a si ou a outrem em particular; ao contrário, a solidariedade crítica tem o objetivo de oferecer ao outro ferramentas concretas para que possa, com seu próprio esforço, sair da situação de vulnerabilidade em que se encontra.

Em suma, tanto a PL de Freire como a BI acreditam na construção de um mundo melhor; ambas as perspectivas pensam ser possível que os mais frágeis, mesmo pressionados pela injustiça e pela malvadez da ética de mercado, lutem para a construção de uma sociedade diferente, uma sociedade pautada na solidariedade ${ }^{46}$. Essa solidariedade pode ser construída como parte de um projeto educativo social e politicamente comprometido, que se preste ao desenvolvimento de disposições e do exercício contínuo da participação, do diálogo e da democracia que, necessariamente, resultará na responsabilidade e engajamento de cada um e na generosidade ou amorosidade consigo mesmo e com os outros ${ }^{47}$.

\section{Considerações finais}

A BI tem como um de seus objetivos básicos a defesa das causas sociais; emprestando as palavras de Freire, tem um compromisso claro em defesa dos "condenados da terra" ${ }^{7}$. Não poderia ser diferente. A pedagogia política de Freire e a BI partilham do mesmo compromisso com a liberdade, agregado ao respeito pela alteridade, ao desejo de resgatar princípios que garantam a dignidade humana, a indignação contra as injustiças, enfim, a necessidade de busca pela justiça social.

A PL de Freire e a BI partilham da mesma ideia de que a educação é uma das formas mais eficazes de intervenção no mundo. Ambas as teorias, ao apostarem na educação, parecem dispostas a contribuir para que homens e mulheres, como "corpos conscientes", façam suas próprias histórias e definam os próprios destinos, não se deixando determinar por olhares e interesses alheios. De fato, a educação, como projeto problematizador e solidário, tem enorme potencial para mobilizar, pois favorece a tomada de consciência e o pleno desenvolvimento da consciência crítica, com vistas à busca do comprometimento individual e coletivo, capaz de conduzir efetivamente os oprimidos à conquista das condições adequadas aos seus processos de humanização e libertação.

Enfim, como propostas políticas, a $\mathrm{BI}$ e a $\mathrm{PL}$ conclamam todos os homens e mulheres a intervir na realidade, assumindo a luta por um mundo pautado nas éticas do compromisso e da solidariedade. Concretamente, o desafio será dar continuidade às reflexões aqui iniciadas. Somente um aprofundamento continuado indicará as possibilidades de aplicação conjunta da ética universal defendida por Freire e os princípios trabalhados pela $\mathrm{BI}$ - especialmente aqueles presentes na DUBDH ${ }^{48}$ - como ferramentas e mecanismos na busca pela cidadania e pelo respeito aos direitos de todas as pessoas e grupos de construírem suas vidas com dignidade, autonomia e liberdade.

Trabalho desenvolvido durante o curso de doutorado do programa de pós-graduação em Bioética da Faculdade de Ciências da Saúde/Cátedra Unesco de Bioética, Universidade de Brasília (UnB), Brasília, Distrito Federal, Brasil.

\section{Referências}

1. Organização das Nações Unidas para a Educação, a Ciência e a Cultura. Declaração universal sobre bioética e direitos humanos. [Internet]. Paris: Unesco; 2005 (acesso 10 abr. 2014). Disponível: http://unesdoc.unesco.org/images/0014/001461/146180por.pdf

2. Garrafa V. O novo conceito de bioética. In: Garrafa V, Kottow M, Saada A, organizadores. Bases conceituais da bioética: enfoque latino-americano. São Paulo: Gaia; 2006. p. 9-16.

3. Garrafa V. Inclusão social no contexto político da bioética. Rev Brasileira Bioética. 2005;1(2):12232.

4. Garrafa V, Porto D. Intervention bioethics: a proposal for peripheral countries in a context of power and injustice. Bioethics. 2003;17(5-6):399-416.

5. Garrafa V. Da bioética de princípios a uma bioética interventiva. Bioética. 2005;13(1):125-34.

6. Porto D, Garrafa V. Bioética de intervenção: considerações sobre a economia de mercado. Bioética. 2005;13(1):111-23. 
7. Freire P. Pedagogia do oprimido. Rio de Janeiro: Paz e Terra; 2005.

8. Freire P. Pedagogia da esperança: um reencontro com a pedagogia do oprimido. Rio de Janeiro: Paz e Terra; 2009.

9. Freire P. Pedagogia da autonomia: saberes necessários à prática educativa. São Paulo: Paz e Terra; 2010. (Coleção Leitura).

10. Garrafa V. Ampliação e politização do conceito internacional de bioética. Rev. bioét. (Impr.). 2012;20(1):9-20.

11. Garrafa V. Op. cit. 2012. p. 11.

12. Garrafa V, Costa SIF, Oselka, G. A bioética no século XXI. In: Garrafa V, Costa SIF, organizadores. A bioética no século XXI. Brasília: UNB; 2000. p. 13-23.

13. Fortes PAC. Reflexão bioética sobre priorização e o racionamento de cuidados de saúde: entre a utilidade social e a equidade. Cad. Saúde Pública. 2008;24(3):696-701.

14. Garrafa V, Porto D. Bioética, poder e injustiça: por uma ética de intervenção. In: Garrafa V, Pessini L, organizadores. Bioética: poder e injustiça. São Paulo: Loyola/Centro Universitário São Camilo/ SBB; 2003. p. 35-44.

15. Bascope CV. El sentido de la muerte en la cosmovisión andina: el caso de los valles andinos de cochabamba. Chungará (Arica). 2001;33(2):271-7.

16. Garrafa V, Porto D. Op. cit. 2003. p. 402.

17. Nascimento WF, Garrafa V. Por uma vida não colonizada: diálogo entre bioética de intervenção e colonialidade. Saúde Soc. 2011;20(2):287-99.

18. Castro MS. Bioética, investigación y salud pública, desde una perspectiva social. Rev Cuba Salud Pública. 2007;33(1):1-10.

19. Garrafa V. Op. cit. 2005. p. 127.

20. Banderas AG. Bioética de Intervención. In: Correa FJL, coordinador. Bioética y sociedad en Latinoamérica. Santiago de Chile: Fundación Interamericana Ciencia y Vida; 2012. p. 71-5.

21. Correa FJL. Bioética institucional y social en Latinoamérica. In: Correa FJL, coordinador. Bioética y Sociedad en Latinoamérica. Santiago de Chile: Fundación Interamericana Ciencia y Vida; 2012. p. 5-6.

22. Garrafa V. Op. cit. 2005. p. 130.

23. Selli L, Garrafa V. Bioética, solidariedade crítica e voluntariado orgânico. Rev Saúde Pública. 2005;39(3):473-8.

24. Selli L, Garrafa V. Solidariedade crítica e voluntariado orgânico: outra possibilidade de intervenção societária. Hist Ciênc Saúde Manguinhos. 2006;13(2):239-51.

25. Selli L, Garrafa V, Junges JR. Beneficiários do trabalho voluntário: uma leitura a partir da bioética. Rev Saúde Pública. 2008;42(6):1.085-9.

26. Selli L, Garrafa V. Op. cit. 2005. p. 477.

27. Schramm RF. Bioética da proteção: ferramenta válida para enfrentar problemas morais na era da globalização. Rev. bioét. (Impr.). 2008;16(1):11-23.

28. Freire P. Pedagogia da indignação: cartas pedagógicas e outros escritos. São Paulo:Unesp; 2000. p. 134.

29. Freire P. Pedagogia da tolerância. São Paulo: Unesp; 2004.

30. Freire P. Op. cit. 2010. p. 16.

31. Freire P. Op. cit. 2000. p. 132.

32. Freire P. Op. cit. 2010. p. 128.

33. Freire P. Op. cit. 2005. p. 23.

34. Machado RC. Autonomia. In: Streck DR, Redin E, Zitkoski JJ, organizadores. Dicionário Paulo Freire. Belo Horizonte: Autêntica; 2008. p. 56-9.

35. Freire P. Op. cit. 2010. p. 107.

36. Dussel E. Ética da libertação: na idade da globalização e da exclusão. $4^{a}$ ed. Petrópolis: Vozes; 2012.

37. Arendt H. Sobre a violência. Rio de Janeiro: Civilização Brasileira; 2009.

38. Freire P. Op. cit. 2004. p. 130.

39. Garrafa V. Op. cit. 2005. p. 131.

40. Freire P. Op. cit. 2005. p. 23.

41. Freire P. Educação como prática da liberdade. 14a ed. Rio de Janeiro: Paz e Terra; 2011.

42. Fanon F. Os condenados da terra. Juiz de Fora: UFJF; 2005.

43. Freire P. Op. cit. 2000. p. 130.

44. Porto D. Bioética de intervenção: retrospectiva de uma utopia. In: Garrafa V, Porto D, Martins GZ, Barbosa SN, organizadores. Bioéticas, poderes e injustiças: 10 anos depois. Brasília: CFM/Cátedra Unesco de Bioética/SBB; 2012. p. 109-26.

45. Selli L, Garrafa V. Solidariedade crítica e voluntariado orgânico. In: Junges JR, Garrafa V, organizadores. Solidariedade crítica e cuidado: reflexões bioéticas. São Paulo: Loyola/São Camilo; 2011. p. 13-21.

46. Angelim MLP. Pedagogia de la liberación. In: Tealdi JC, director. Diccionario latinoamericano de bioética. Bogotá: Universidad Nacional de Colombia/Redbioética Unesco; 2008. p. 11-2.

47. Freire P. Pedagogia do compromisso: América Latina e educação popular. Indaiatuba: Villa das Letras; 2008. (Coleção Dizer a Palavra). 
48. Santos IL, Garrafa V. Análise da declaração universal sobre bioética e direitos humanos da Unesco à luz da ética de Paulo Freire. Revista Redbioética/Unesco. 2011;1(3):130-5.

\section{Participação dos autores}

Ivone L. Santos participou da organização e desenvolvimento do estudo, discussão, coleta bibliográfica e redação final do artigo. Helena E. Shimizu, como coorientadora, participou da organização metodológica do estudo. Volnei Garrafa, como orientador da pesquisa, foi o responsável por seu planejamento e participou em todas as fases do trabalho.

Recebido: 22.3.2014

Revisado: $\quad 19.5 .2014$

Aprovado: 11.7 .2014 